\title{
Research on Influencing Factors of the Safety Reliability of Ships under Emergency Conditions Driven By GMDSS
}

\author{
Xiuping Sui \\ Traffic Information Engineering, Shandong Jiaotong University
}

\author{
Keywords: Influencing Factors; Safety Reliability; Emergency Conditions
}

\begin{abstract}
The ship navigation safety evaluation is to estimate the influencing factors of ship's safe navigation and evaluation, which is to constitute the indicator system of ship navigation safety of risk estimate and evaluation. The essential purpose for the evaluation is whether it constitute the index system of ship navigation safety and whether it meets safety requirements. According to the result of evaluation, we have adjusted the index system of the elements to strengthen the navigation safety measures and reduce the risk of larger accident probability.
\end{abstract}

\section{Introduction}

At present, the ship navigation safety evaluation is mainly to find the cause of the accident, summing up experience and lessons, and take measures to prevent accidents, this method can prevent accidents to reduce the risk, but also it has many deficiencies, mainly displays in: with experience and intuition to know and deal with the ship navigation safety danger and hidden dangers existing in the index system, using the general concept of "security" or "unsafe" is more, the lack of quantitative expression of ship navigation safety. From considering the ship navigation, the safety measures has been based on elements of a system, when elements have larger changes in the system, the existing methods and experience will have bigger limitation, that is lack of overall analysis of the index system of navigation safety. Therefore, to systematically and comprehensively solve the security problem, evaluation of ship navigation safety accidents mainly adopts the absolute index. We have found it difficult to make the right assessment of the state change of ship navigation safety. The ship navigation safety evaluation is to estimate the influencing factors of ship's safe navigation and evaluation, which is to constitute the indicator system of ship navigation safety of risk estimate and evaluation. The essential purpose for the evaluation is whether it constitute the index system of ship navigation safety and whether it meets safety requirements. According to the result of evaluation, we should adjust the index system of the elements, to strengthen the navigation safety measures and reduce the risk of larger accident probability.

\section{Fuzzy Comprehensive Evaluation}

The fuzzy comprehensive evaluation is an object of a given considering various fuzzy factors in the evaluation and decision method. Because the ship on the voyage influence the navigational safety of numerous factors, and the vast majority of ambiguity, Therefore, it is in line with the actual situation that fuzzy mathematics comprehensive evaluation method is used to evaluate the navigation safety of ships.

\section{Structure of Ship Navigation Safety Evaluation Index System}

The ship navigation safety evaluation index system has the first class index including personal factors, environmental factors, ship factors and management factors. For the second index, personal factors have work experience, knowledge, literacy, experience, accident, fault management. Environmental factors include cabin environment; living cabin weather and sea conditions, port and navigation conditions, traffic density. Ship factors have ship technical status, ship maintenance status; equipment reliability. Management factors have security management, management onshore management, training management and rest time. 


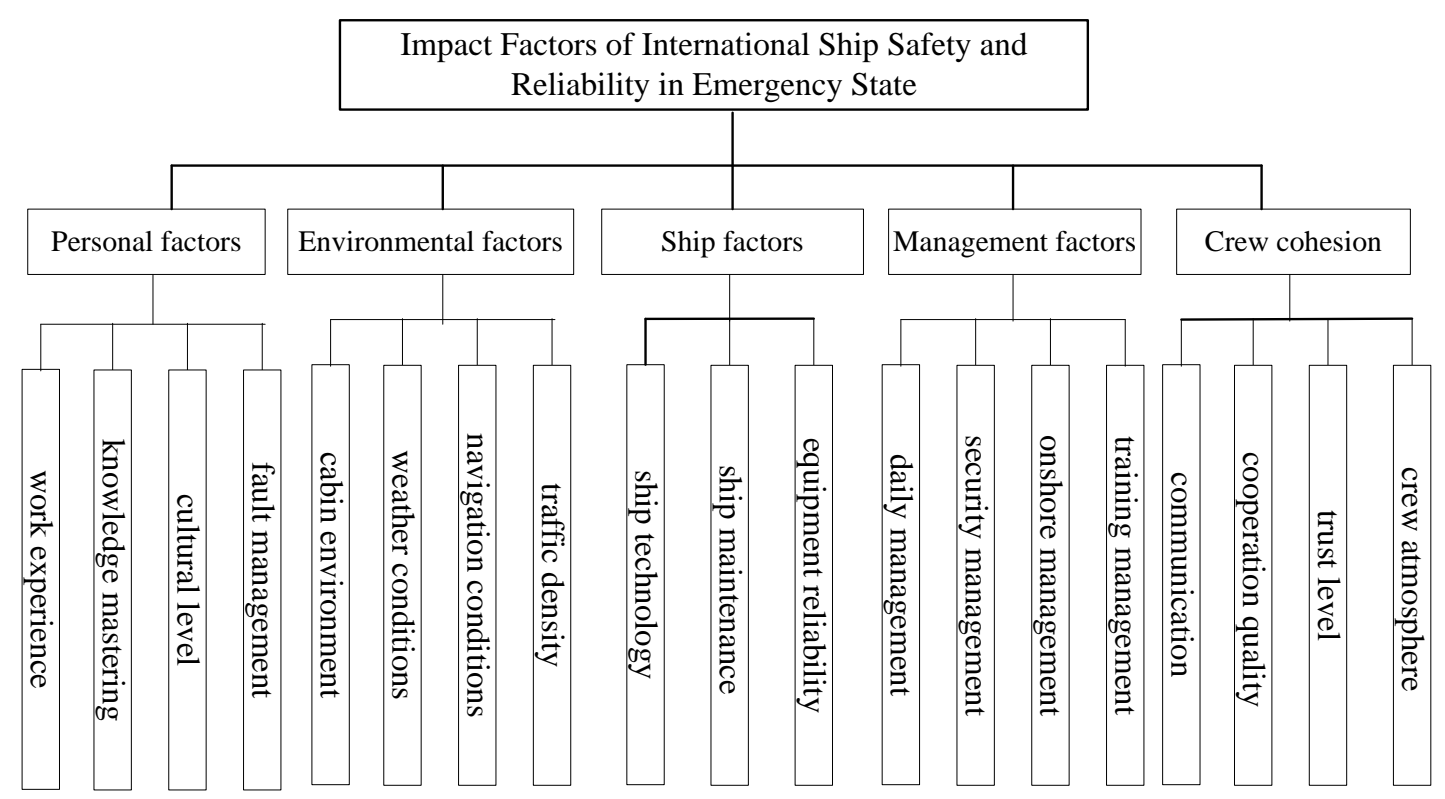

Figure 1. Safety Reliability Of International Ships Influencing Factors

\section{Setup Judgment Matrices}

The hierarchical structure of this paper is based on the evaluation index system of Safety Reliability Of International Ships Influencing Factors, and test the consistency, and weigh the value of each index layer as follow:

A0
$\left[\begin{array}{ccccc}1 & 1 / 7 & 1 / 5 & 1 / 3 & 1 / 2 \\ 7 & 1 & 2 & 3 & 4 \\ 5 & 1 / 2 & 1 & 2 & 4 \\ 3 & 1 / 3 & 1 / 2 & 1 & 2 \\ 2 & 1 / 4 & 1 / 4 & 1 / 2 & 1\end{array}\right]$

$A 0: W=(0.0525,0.4263,0.2792,0.1526,0.0894)$

$A 0: C I=0.0128, C R=0.0114<0.1 ; \lambda_{\max }=5.051$

Al

$\left[\begin{array}{cccc}1 & 2 & 5 & 1 / 3 \\ 1 / 2 & 1 & 2 & 1 / 5 \\ 1 / 5 & 1 / 2 & 1 & 1 / 6 \\ 3 & 5 & 6 & 1\end{array}\right]$

$A 1: W=(0.2508,0.1211,0.0677,0.5608)$

$A 1: C I=0.0251, C R=0.0278<0.1 ; \lambda_{\max }=4.076$,

A2

$$
\left[\begin{array}{cccc}
1 & 1 / 5 & 1 / 3 & 1 / 6 \\
5 & 1 & 3 & 1 / 2 \\
3 & 1 / 3 & 1 & 1 / 5 \\
6 & 2 & 5 & 1
\end{array}\right]
$$

$A 2: W=(0.0621,0.3014,0.1272,0.5094)$ 
$A 2: C I=0.0317, C R=0.0352<0.1 ; \quad \lambda_{\max }=4.0951$

A3

$\left[\begin{array}{ccc}1 & 3 & 1 / 3 \\ 1 / 3 & 1 & 1 / 5 \\ 3 & 5 & 1\end{array}\right]$

$A 3: W=(0.2605,0.1062,0.6333)$

$A 3: C I=0.0194, \quad C R=0.0328<0.1 ; \quad \lambda_{\max }=3.0387$

A4
$\left[\begin{array}{cccc}1 & 1 / 6 & 1 / 4 & 1 / 3 \\ 6 & 1 & 2 & 3 \\ 4 & 1 / 2 & 1 & 2 \\ 3 & 1 / 3 & 1 / 2 & 1\end{array}\right]$

$A 4: W=(0.0685,0.4839,0.2795,0.1680)$

$A 4: C I=0.0104, \quad C R=0.0115<0.1 ; \quad \lambda_{\max }=4.0311$

A5

$\left[\begin{array}{cccc}1 & 1 / 5 & 1 / 3 & 2 \\ 5 & 1 & 2 & 5 \\ 3 & 1 / 2 & 1 & 3 \\ 1 / 2 & 1 / 5 & 1 / 3 & 1\end{array}\right]$

$A 5: W=(0.1208,0.5132,0.2811,0.0849)$

$A 5: C I=0.0219, \quad C R=0.0243<0.1 ; \quad \lambda_{\max }=4.0657$

In the first class index including personal factors, environmental factors, ship factors and management factors, personal factors is important. For the second index, Among personal factors, work experience is much more important. Among environmental factors weather and sea conditions is a bit important. Among environmental factors, weather condition is important. Among ship factors, equipment reliability is important. Among management factors, security management is a bit important.

\section{Acknowledgements}

National Education Science 13th Five-Year Plan 2016 Key topic of the Ministry of Education "STCW New Convention Driven International Applied Talent Cultivation Theory and Practice Research" approved DJA160380

\section{Conclusion}

Fuzzy comprehensive evaluation method of ship navigation safety evaluation is from the index system of ship navigation safety factors and analysize the factors of inner link, also consider the external conditions affecting the safety of ship navigation and environmental conditions influence on navigation safety of differences. Through the quantitative calculation of the model, the ship navigation safety evaluation index include the main factors and secondary factors for shipping companies, the maritime administrative department and waterways, this can provide reliable and detailed information and data to avoid safety measures of empirical and blindness. We apply fuzzy comprehensive evaluation method to evaluate the ship sailing index factors, not only for 
enriching the ship navigation safety management theory, scientific and reasonable understanding of the importance of affect ship navigation safety, but also improving the working methods, better the management of ship navigation safety.

\section{References}

[1] Roberto Linares, Jo Choi-Nurvitadhi,Svetlana Cooper, YoungYoon Ham, Jane E. Ishmael, Ann Zweber. Personnel training and patient education in medical marijuana dispensaries in Oregon. Journal of the American Pharmacists Association, 2016(12), pp.270-273.

[2] Dingyuemin. Research on the Evaluation Method of Personnel Quality Based on Medical Personnel Competence Model. Human Resources Management, 2015(2), pp.195-196.

[3] Feng D Y. On the Seafarer's Training of the Transitional Period of Implementing the STCW 78 / 10Convention. Journal of Qingdao Ocean Shipping Mariners College, 2013.

[4] Marco T, Tiziana R, Claudia C. Being Social for Social:A Co-creation Perspective. Journal of Service Theory and Practice, 2015,25(2), pp.198-219.

[5] Assaf AG, Barros C, Sellers-Rubio R. Efficiency determinants in retail stores: A Bayesian framework. Omega. 2011, 39(3), pp.283-292.

[6] Roberto Linares, Jo Choi-Nurvitadhi,Svetlana Cooper, Young Yoon Ham, Jane E. Ishmael, Ann Zweber. Personnel training and patient education in medical marijuana dispensaries in Oregon. Journal of the American Pharmacists Association, 2016(12), pp.270-273.

[7] Dingyuemin. Research on the Evaluation Method of Personnel Quality Based on Medical Personnel Competence Model. Human Resources Management, 2015(2), pp.195-196.

[8] Feng D Y. On the Seafarer's Training of the Transitional Period of Implementing the STCW 78 / 10Convention. Journal of Qingdao Ocean Shipping Mariners College, 2013.

[9] Frederic P, Philipp K, Roger S. Experience Co-creation in Financial Services:An Empirical Exploration. Journal of Service Management, 2015, 26 (2), pp.295-320.

[10] Yu Huixian. Recruitment Based on Competency Model[J].Chinese and Foreign Exchanges, 2017,(17): 30

[11] Assante M, Candela L, Castelli D. Are Scientific Data Repositories Coping with Research Data Publishing. Data Science Journal, 2016(15), pp.1-24.

[12] Dnyandeo Dattatraya Shinde, Ramjee Prasad. Application of AHP for Ranking of Total Productive Maintenance Pillars. Wireless Personal Communications, 2018, 100 (2), pp.449-462.

[13] Saeid Maknouni, Mohammad Zare, Ezzatollah Raeisi. Determining the hard rock groundwater pathway in Golgohar complex formation using hydrochemical data in AHP. Arabian Journal of Geosciences, 2018, 11 (8), pp.1-16.

[14] Arthur S. Levine, Margaret C. McDonald, Charles E. Bogosta. Sino-U.S. partnerships in research, education, and patient care: The experience of the University of Pittsburgh and UPMC. Science China Life Sciences, 2017, 60 (10), pp.1150-1156. 